\title{
Enigmatic dinosaur precursors bridge the gap to the origin of Pterosauria
}

\author{
Martín D. Ezcurra ${ }^{1,2 \bowtie}$, Sterling J. Nesbitt ${ }^{3}$, Mario Bronzati ${ }^{4}$, Fabio Marco Dalla Vecchia, ${ }^{5,6}$, \\ Federico L. Agnolin ${ }^{7,8}$, Roger B. J. Benson ${ }^{9}$, Federico Brissón Egli ${ }^{7}$, Sergio F. Cabreira ${ }^{10}$, \\ Serjoscha W. Evers ${ }^{9,11}$, Adriel R. Gentil', Randall B. Irmis ${ }^{12,13}$, Agustín G. Martinelli', \\ Fernando E. Novas ${ }^{7}$, Lúcio Roberto da Silva ${ }^{10}$, Nathan D. Smith ${ }^{14}$, Michelle R. Stocker ${ }^{3}$, \\ Alan H. Turner ${ }^{15}$ \& Max C. Langer ${ }^{4}$
}

Pterosaurs were the first vertebrates to evolve powered flight ${ }^{1}$ and comprised one of the main evolutionary radiations in terrestrial ecosystems of the Mesozoic era (approximately 252-66 million years ago), but their origin has remained an unresolved enigma in palaeontology since the nineteenth century ${ }^{2-4}$. These flying reptiles have been hypothesized to be the close relatives of a wide variety of reptilian clades, including dinosaur relatives ${ }^{2-8}$, and there is still a major morphological gap between those forms and the oldest, unambiguous pterosaurs from the Upper Triassic series. Here, using recent discoveries of well-preserved cranial remains, microcomputed tomography scans of fragile skull bones (jaws, skull roofs and braincases) and reliably associated postcrania, we demonstrate that lagerpetids-a group of cursorial, non-volant dinosaur precursors-are the sister group of pterosaurs, sharing numerous synapomorphies across the entire skeleton. This finding substantially shortens the temporal and morphological gap between the oldest pterosaurs and their closest relatives and simultaneously strengthens the evidence that pterosaurs belong to the avian line of archosaurs. Neuroanatomical features related to the enhanced sensory abilities of pterosaurs ${ }^{9}$ are already present in lagerpetids, which indicates that these features evolved before flight. Our evidence illuminates the first steps of the assembly of the pterosaur body plan, whose conquest of aerial space represents a remarkable morphofunctional innovation in vertebrate evolution.

Pterosaurs are deeply rooted in popular culture, are frequently portrayed in books and films ${ }^{10}$, and include the largest flying animals ever known ${ }^{11}$. Their evolutionary history spans more than 150 million years, ending at the close of the Mesozoic era ${ }^{10,11}$. The oldest pterosaurs are from the Upper Triassic series (219-201.3 million years ago) of Europe and North America ${ }^{12,13}$, and the clade diversified into multiple ecomorphologically disparate groups by the Middle-Late Jurassic epochs ${ }^{11,14}$. The oldest recognized pterosaurs already had a highly specialized body plan linked to their ability to fly ${ }^{12,15}$, which was conserved in all pterosaurs: shoulder girdle with strongly posteroventrally enlarged coracoid braced with the sternum and laterally facing glenoid fossa; forelimb with pteroid bone and hypertrophied fourth digit supporting a membranous wing; and pelvic girdle with prepubic bone and strongly developed preacetabular process ${ }^{1}$. This highly modified anatomy results in a large morphological gap between pterosaurs and all other known
Mesozoic reptiles. To complicate matters, early pterosaur specimens are small, scarce and generally represented by taphonomically compressed, almost bidimensional partial skeleton ${ }^{12}$. These preservational problems and the absence of fossils with transitional morphologies have made the origin of pterosaurs one of the most elusive questions in vertebrate evolution for more than 200 years.

Quantitative phylogenetic analyses have generally agreed that pterosaurs fall within the lineage of Archosauria (that is, the least inclusive clade that contains birds and crocodylians) leading to dinosaurs (that is, Pan-Aves = Avemetatarsalia $)^{2,3,5-8}$. However, some studies have alternatively recovered pterosaurs as the sister group to all other pan-archosaurs ${ }^{16}$, among tanystropheid archosauromorphs ${ }^{17}$, among non-archosaurian archosauriforms ${ }^{18}$ or sister to the probable stem-diapsid drepanosauromorphs ${ }^{19}$. New fossil discoveries over the past few years have greatly increased the understanding of the 


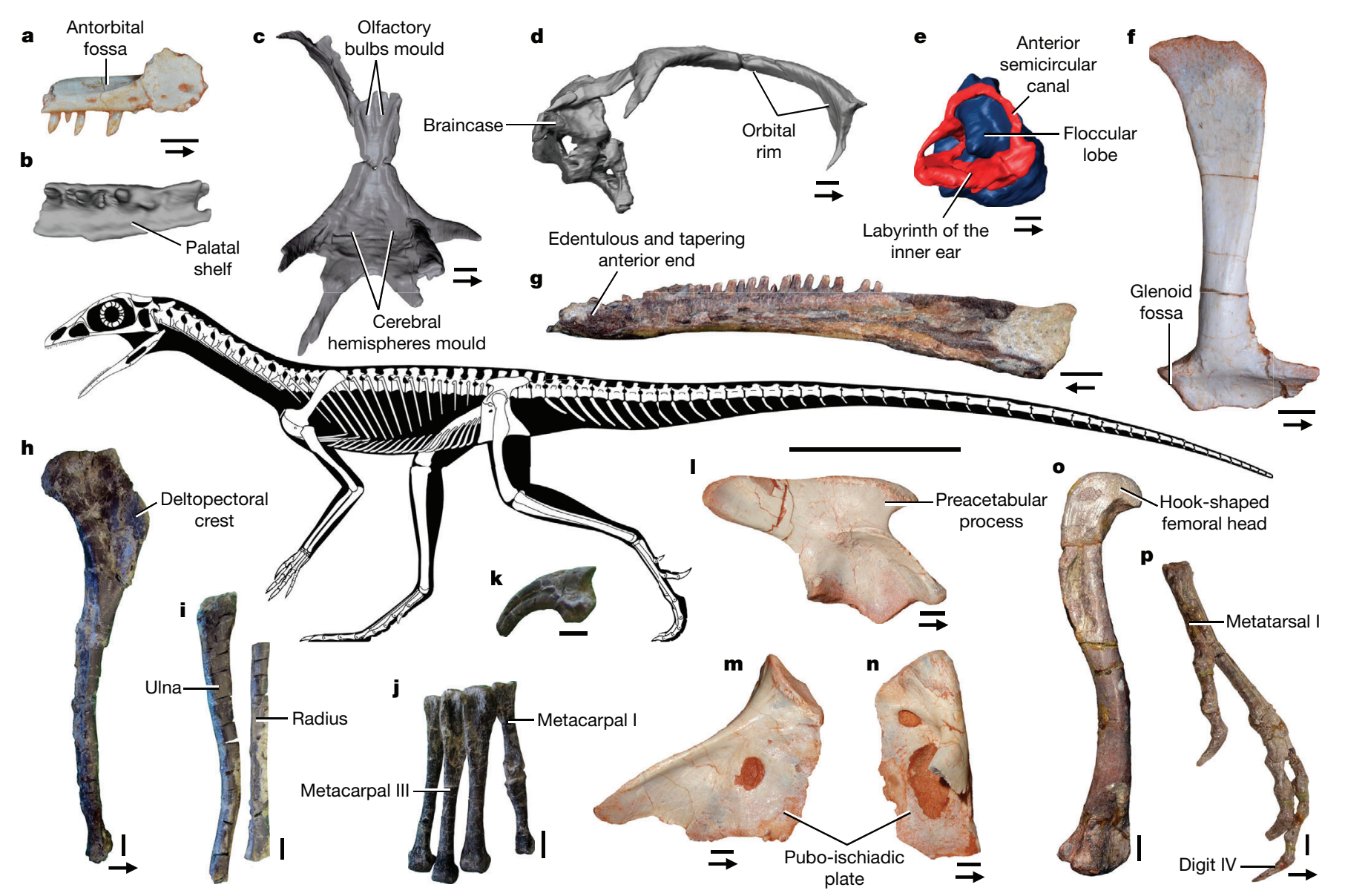

Fig. 1 Newly discovered and selected bones characterizing the lagerpetid body plan. a, b, Partial right maxilla. c, Skull roof. d, Skull roof and braincase. e, Cranial endocast.f, Right scapula.g, Left dentary. h, Left humerus. i, Partial ulna and radius.j, metacarpals I-IV and phalanx 1 of digit I. k, Ungual of manual digit IV.I, Right ilium. m, Right ischium. n, Left pubis. o, Femur. p, Pes. Images show lateral $(\mathbf{a}, \mathbf{f}, \mathbf{g}, \mathbf{k}-\mathbf{m})$, ventral $(\mathbf{b}, \mathbf{c})$, right lateral $(\mathbf{d}, \mathbf{e})$, medial $(\mathbf{h}, \mathbf{i}, \mathbf{n}, \mathbf{p})$,

dorsal (j) and posteromedial (o) views. a-f, $\mathbf{l}-\mathbf{n}$, lxalerpeton (ULBRA-PVT059). g, o, p, Lagerpeton (PVL 4625 (g) and PVL $4619(\mathbf{o}, \mathbf{p})$ ). h-k, Dromomeron romeri (GR 238). Arrows indicate the anterior direction. Scale bars, $2 \mathrm{~mm}(\mathbf{a}, \mathbf{b}, \mathbf{e}), 3 \mathrm{~mm}$ $(\mathbf{c}, \mathbf{d}, \mathbf{f}, \mathbf{g}, \mathbf{k}-\mathbf{n})$ and $5 \mathrm{~mm}(\mathbf{h}-\mathbf{j}, \mathbf{o}, \mathbf{p})$. Skeletal reconstruction by S. Hartman in collaboration with the authors, based on Lagerpeton, Ixalerpeton and $D$. romeri.

early evolution of Pan-Aves and of the assembly of the dinosaur body plan $^{8,20,21}$. Nevertheless, a clear morphological gap still remains between pterosaurs and other pan-avians. Here, using new and existing specimens of the enigmatic pan-avian clade Lagerpetida ${ }^{21}$, we report on a previously undocumented combination of features that reduces the morphological gap between pterosaurs and other reptiles, clarifying the phylogenetic placement of Pterosauria within Pan-Aves. We present anatomical information from across the entire skeleton that demonstrates that lagerpetids are the closest-known evolutionary relatives of pterosaurs. This information derives from detailed first-hand observation of lagerpetid specimens, enhanced by three-dimensional reconstructions from microcomputed tomography scans.

Lagerpetids are small to medium-sized (usually less than $1 \mathrm{~m}$ long), gracile and cursorial reptiles from Middle-Upper Triassic rocks of South and North America and Madagascar ${ }^{21,22}$. Previous knowledge of lagerpetid anatomy was mostly limited to vertebrae, hindlimbs and a few cranial bones. Our data are based on improved observations across

Lagerpeton and Ixalerpeton have an edentulous anterior end that tapers to a point (Figs.1g, 2e), resembling the condition in the early pterosaurs Seazzadactylus, Carniadactylus and Raeticodactylus ${ }^{12,23,24}$ (Fig. 2f), and most silesaurids ${ }^{20}$. The anterior region of the lagerpetid dentary is ventrally curved (Fig. 1g), similar to those of the early pterosaurs Austriadactylus and Peteinosaurus ${ }^{12,23,24}$. The lower jaw of Lagerpeton preserves articulated dentaries and lack splenials (Extended Data Fig. 2); the latter bone is fused to the dentary or restricted to the mid-point of the medial surface of the mandible in pterosaurs ${ }^{13}$. Lagerpeton and Ixalerpeton have 26-27 dentary tooth positions, sharing the high tooth count (more than 20 teeth) of several early pterosaurs ${ }^{13,23,24}$ (Figs. 1g, 2e, f and Extended Data Figs. 1, 2). The dentary tooth crowns of these lagerpetids have convex mesial and distal margins, and middle-distal crowns possess a large and tall central cusp flanked by mesiodistally aligned, small accessory cusps (Fig. 2g and Extended Data Fig. 2). Multicusped tooth crowns are rare among archosauriforms, but also occur in several early pterosaurs (for example, Austriadraco, 

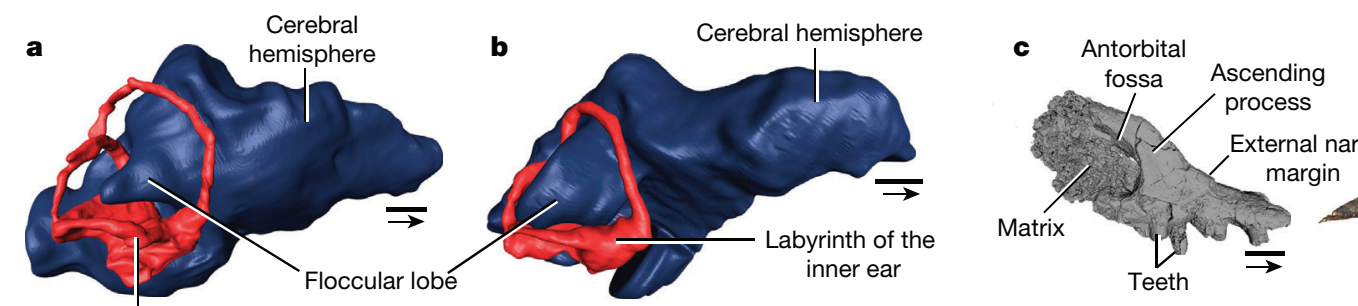

d Antorbital fossa
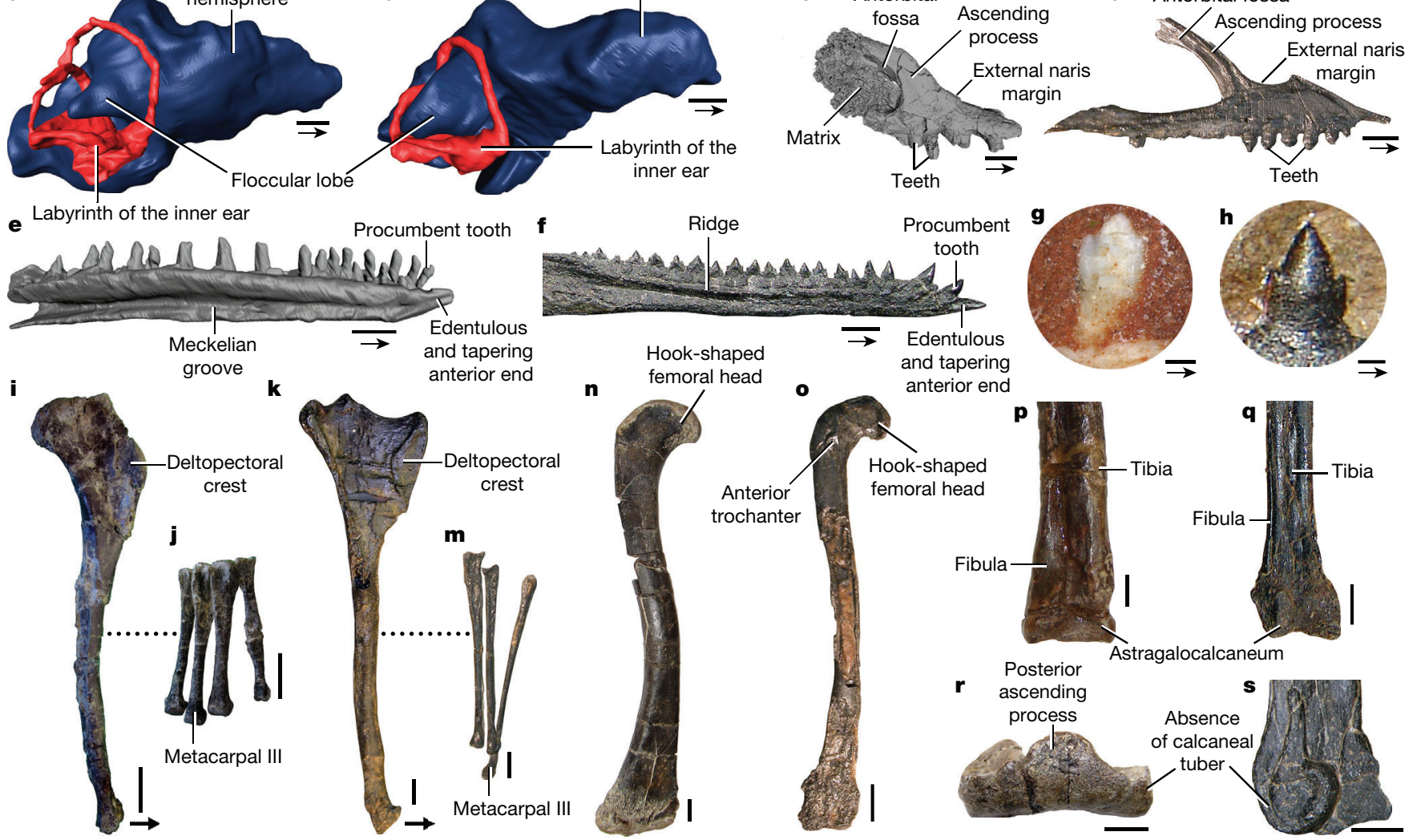

Fig. 2 | Key comparisons between pterosaur and lagerpetid cranial

endocasts and skeletal elements. a, b, Cranial endocasts. c, Partial right maxilla.d, Left maxilla (reversed).e, Left dentary.f, Right dentary. g, h, Dentary tooth crowns. i, k, Left humeri.j, Partial manus. m, Metacarpals I-III.

$\mathbf{n}, \mathbf{o}$, Femora (n, left, reversed; o, right). p, q, s, Right distal portion of tibia, fibula and astragalocalcaneum. $\mathbf{r}$, Right astragalocalcaneum. Images show right lateral $(\mathbf{a}, \mathbf{b})$, lateral $(\mathbf{c}, \mathbf{d}, \mathbf{f})$, medial $(\mathbf{e}, \mathbf{i}, \mathbf{k})$, labial $(\mathbf{g}, \mathbf{h})$, dorsal $(\mathbf{j})$, dorsal or ventral $(\mathbf{m})$, anterolateral $(\mathbf{n}, \mathbf{o}, \mathbf{s})$, anterior $(\mathbf{p}, \mathbf{q})$ and posterior $(\mathbf{r})$ views.

a, Lagerpetid D. gregorii (TMM 31100-1334). b, Pterosaur Allkaruen (MPEF-PV 3613). c, Lagerpetid Kongonaphon (UA 10618). d, k, m, o, Pterosaur Raeticodactylus (BNM 14524). e, g, Lagerpetid Ixalerpeton (ULBRA-PVT059). h, q, Pterosaur Austriadraco (SNSB-BSPG 1994 I 51). f, Pterosaur Seazzadactylus (MFSN 21545). i, , , , n, r, Lagerpetid D. romeri (GR $238(\mathbf{i}, \mathbf{j})$, GR 218 (n) and GR 223 (r)). p, Lagerpetid Lagerpeton (PULR 06). s, Pterosaur Peteinosaurus (MCSNB 3496). Arrows indicate the anterior direction. Scale bars, $3 \mathrm{~mm}(\mathbf{a}, \mathbf{b}, \mathbf{f}, \mathbf{q}), 2 \mathrm{~mm}$ $(\mathbf{c}, \mathbf{e}, \mathbf{s}), 5 \mathrm{~mm}(\mathbf{d}, \mathbf{k}-\mathbf{p}, \mathbf{r}), 0.3 \mathrm{~mm}(\mathbf{g}, \mathbf{h})$ and $1 \mathrm{~cm}(\mathbf{i}, \mathbf{j})$.

other archosauromorphs $s^{6,7}$. The cranial endocasts of $D$. gregorii and Ixalerpeton show strongly developed and posterolaterally tapering cerebellar floccular lobes, which resemble the even more developed floccular lobes of pterosaurs ${ }^{9,25}$ (Figs. 1e, 2a, b). The olfactory tract of Ixalerpeton is long and ends in broad olfactory bulbs (Fig. 1c), retaining the ancestral condition of Archosauromorpha ${ }^{7}$, whereas these structures are strongly reduced in pterosaurs ${ }^{9,25}$. In the inner ear, the portion of the semicircular canals of the endosseous labyrinth of $D$. gregorii, Ixalerpeton, pterosaurs and some early eusaurischian dinosaurs are taller than anteroposteriorly long, with an anterior semicircular canal that forms a considerably longer arc than the posterior semicircular canal (Fig. 2a, b, Supplementary Information).

The forelimbs of Dromomeron romeri and pterosaurs share a forearm that is longer than the humerus, including a proportionally elongated metacarpus (metacarpal III-humerus length ratio $>0.35$ ) (Fig. 2i-m). The manual digits of $D$. romeri are longer than their respective metacarpal and at least one digit has a trenchant claw (Fig. 1k),

Dimorphodon $)^{12,23}$ (Fig. 1l-n and Extended Data Fig. 3b, c), but not in most other archosaurs ${ }^{6,7}$.

The femora of lagerpetids and early pterosaurs (for example, Raeticodactylus, Peteinosaurus and Dimorphodon) share a hook-shaped proximal head (Figs. 1o, 2n, o and Extended Data Fig. 3c, d). A co-ossified astragalus and calcaneum is present in both lagerpetids and pterosaurs (Fig. 2p-s), but also in heterodontosaurid ornithischians and early neotheropods ${ }^{6,7}$. The absence of both a posterior groove on the astragalus and a calcaneal tuber is shared by pterosaurs and lagerpetids (Fig. $2 \mathrm{r}, \mathrm{s}$ ) and independently arose in some silesaurids and early dinosaurs ${ }^{6}$.

The new anatomical information available for lagerpetids was scored in an expanded version of a comprehensive phylogenetic data matrix focused on Permo-Triassic pan-archosaurs 7 . Our data matrix comprises 157 species (or diagnostic specimens) scored across 822 characters, including all currently valid lagerpetid species, 9 Triassic and 4 Jurassic pterosaurs, 13 early dinosauriforms, and most non-archosaurian 


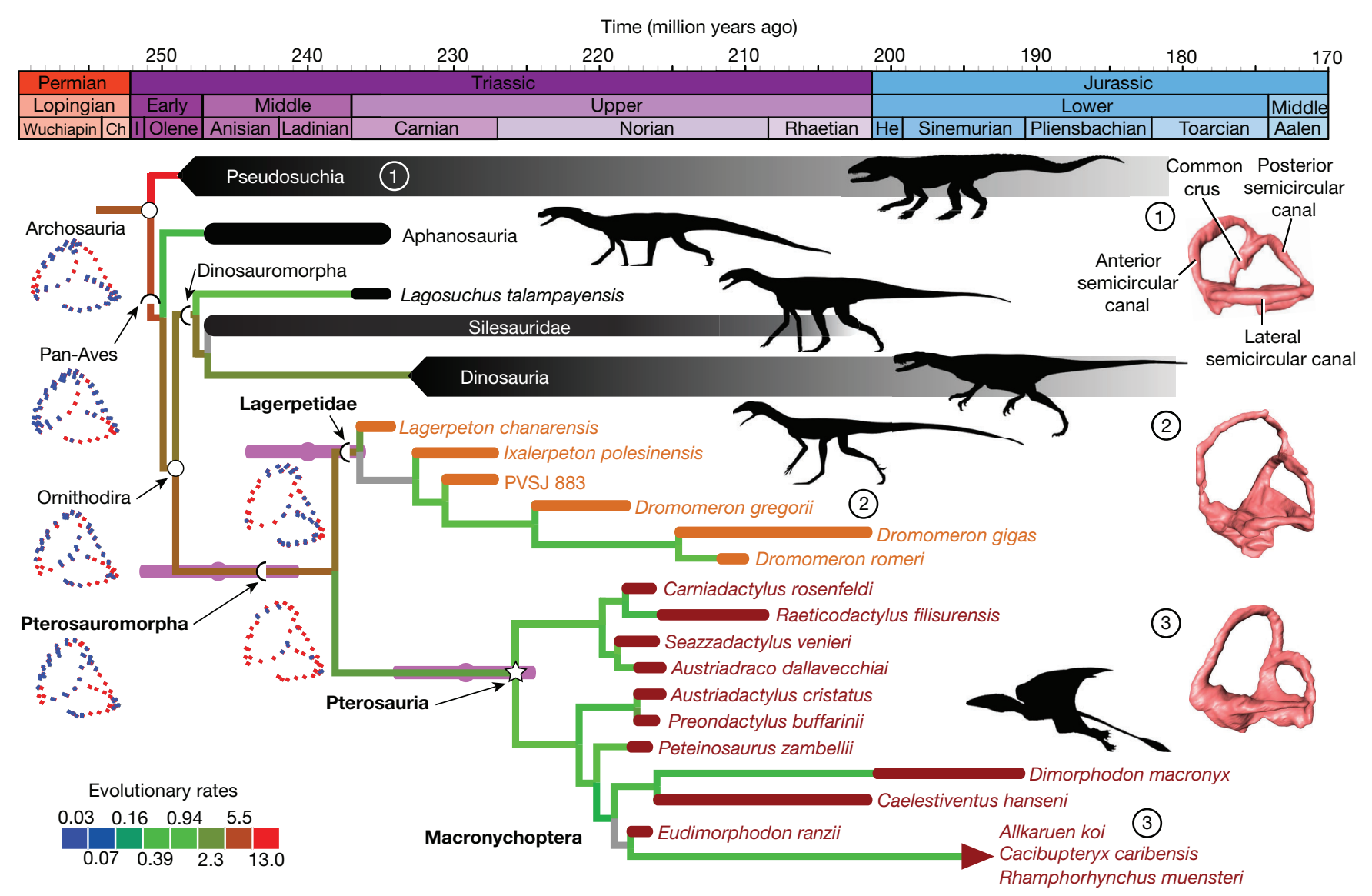

Fig. 3 | Time-calibrated reduced strict consensus tree (after a posteriori pruning of Kongonaphon) focused on Pterosauria and Lagerpetidae. Red dotted structures are ancestral optimizations of the labyrinth of the inner ear (blue lines are apomorphic displacements). Violet bars indicate node temporal calibration after Bayesian analysis. White-fill circles indicate node-based

model that incorporates taxon ages using a fossilized birth-death process (posterior probability $=0.99$ for the lagerpetid-pterosaur clade) (Extended Data Fig. 6). A minimum of 33 synapomorphies distrib uted across the skeleton provide strong support for the Lagerpetidae and Pterosauria clade (= Pterosauromorpha). Some of these synapomorphies are unique to pterosauromorphs among early archosaurs, including a subtriangular and dorsoventrally tall floccular fossa of the braincase, a height-anteroposterior length ratio of the semicircular canals of the inner ear $>0.90$, a reduced to absent splenial, strongly ventrally extended pubo-ischiadic plate, and hook-shaped femoral head (a complete list of synapomorphies can be found in the Supplementary Information). Bayesian inference analyses indicate high rates of morphological change during deep pan-avian divergences, including on the branches leading to Pterosauromorpha and Lagerpetidae. These high rates contrast with the more typical 'background' rates found on the branch leading to Pterosauria and its internal branches (Fig. 3). By contrast, higher evolutionary rates occur on the pterosaur branch if we force the more traditional position of lagerpetids closer to dinosaurs (Extended Data Fig. 7). These results strengthen the idea that clades, half-circles stem-based clades and the star an apomorphy-based clade. Labyrinths of the inner ear are in lateral view and belong to (1) Arizonasaurus,

(2) D. gregorii and (3) Allkaruen. Further information is provided in the Supplementary Information. Ch, Changhsingian; I, Induan; He, Hettangian.

23 additional steps are needed to force the more traditional position of lagerpetids as the sister taxon to Dinosauriformes. We also tested previous alternative hypotheses for pterosaur relationships, finding that 44 extra steps are required to place them as non-archosaurian archosauriforms and 64 steps to force their placement as sister taxon to Tanystropheidae (but the Pterosauria and Tanystropheidae clade is sister to Lagerpetidae within Pan-Aves). These results agree with a poorly supported placement of Pterosauria outside Archosauria ${ }^{6,7}$. The possible pterosaur-relative ${ }^{2,3}$, but highly problematic taxon Scleromochlus (Upper Triassic of Scotland), was included in a secondary phylogenetic analysis (Methods) and was recovered as the sister taxon to the Pterosauria and Lagerpetidae clade within Pan-Aves (Extended Data Fig. 4).

Additional cladistic analyses included the geometric morphometric configuration of the labyrinth of the inner ear as a continuous three-dimensional character in an attempt to avoid subjective discrete character states on such a complex structure ${ }^{26}$ (Supplementary Information). The analyses suggest that the inner ear has a strong phylogenetic signal that supports a pterosaur-lagerpetid affinity (Fig. 3 
and highly rounded semicircular canals as a trait combination that is uniquely shared by pterosaurs and lagerpetids (Extended Data Fig. 10c). Lagerpetids and pterosaurs exhibit a strong curvature of the anterior semicircular canal (arc-length versus straight-line ratio $>1.5$ ) that results in an increased radius, which convergently evolved in a few early saurischian dinosaurs and is present in birds. The semicircular canals detect head movements (angular acceleration) and a larger radius increases the sense of equilibrium in primates and birds, and therefore is inferred to be related to arboreal, aerial or other agile forms of terrestrial locomotion and rapid movement $\mathrm{s}^{27}$. Lagerpetids and pterosaurs are the only archosauriforms with a greatly enlarged floccular fossa, representing more than $40 \%$ the height of the endocranial cavity (Fig. 2a, b). A large flocculus might have been important for lagerpetid locomotion or predation, given the connection of this structure with coordination of eye, head and neck movements ${ }^{28}$. In pterosaurs, floccular enlargement has been hypothesized to be important for information processing related to flight ${ }^{9}$. Although not as developed as in pterosaurs, the relatively large lagerpetid flocculus indicates that initial enlargement of that structure occurred along the Pterosauromorphabranch. Thus, the neuroanatomy of lagerpetids has intermediate features between those of pterosaurs and other Triassic archosauriforms and may have paved the way towards the origin of active flight in pterosaurs.

The evolution of other traits associated with the acquisition of flight remains difficult to trace at the base of Pterosauromorpha with the currently available fossil record. Lagerpetid girdles and limbs lack features correlated with the flying behaviour of pterosaurs, for example, a hypertrophied deltopectoral crest of the humerus and wing digit of the manus ${ }^{1}$. However, the strongly recurved manual claws, with an inner curvature of more than $150^{\circ}$ in D. romeri (Fig. $1 \mathrm{k}$ ), suggests that the forelimbs had functions other than ground-dwelling locomotion, such as climbing or acquisition of prey (the inner claw curvature of ground-dwelling birds and squamates ranges from $21.5^{\circ}$ to $125.5^{\circ}$ and in perchers, climbers and predators ranges from $87^{\circ}$ to $\left.170.3^{\circ}\right)^{29}$. Non-archosaurian archosauriforms, early crocodylian-line archosaurs and very probably aphanosaurians (the earliest pan-avians) were all quadrupedal, ground-dwelling animals ${ }^{30}$. Our observations suggest that functional forelimb versatility became widespread in ornithodirans (Fig. 3), allowing the evolution of disparate behaviours such as manual processing of food resources in dinosaurs and active flight in pterosaurs.

The recognition of lagerpetids as the sister taxon to pterosaurs provides a new framework to study the origin of Pterosauria, its specialized body plan and flying abilities. Previous phylogenetic hypotheses implied a long ghost lineage, with a minimum of 28 million years, for Pterosauria ${ }^{8}$. Our results shorten this to about 18 million years, because the oldest lagerpetids come from 237-million-year-old rocks, near the Ladinian-Carnian boundary ${ }^{22}$ (Fig. 3). Along those millions of years, the enhancement of features that were already present in the common ancestor of lagerpetids and pterosaurs allowed the latter group to explore a new adaptive landscape and conquer aerial space, which probably promted their impressive adaptive radiation.

\section{Online content}

Any methods, additional references, Nature Research reporting summaries, source data, extended data, supplementary information, acknowledgements, peer review information; details of author contributions and competing interests; and statements of data and code availability are available at https://doi.org/10.1038/s41586-020-3011-4.

1. Padian, K. The origins and aerodynamics of flight in extinct vertebrates. Palaeontology 28, 413-433 (1985).

2. Padian, K. in Third Symposium on Mesozoic Terrestrial Ecosystems: Short Papers (eds Reif, W.-E. \& Westphal, F.) 163-166 (Atempto, 1984).

3. Sereno, P. C. Basal archosaurs: phylogenetic relationships and functional implications. Soc. Vertebr. Paleontol. Mem. 2, 1-53 (1991).

4. Benton, M. J. Scleromochlus taylori and the origin of dinosaurs and pterosaurs. Phil. Trans. R. Soc. Lond. B 354, 1423-1446 (1999).

5. Gauthier, J. A. Saurischian monophyly and the origin of birds. Mem. Calif. Acad. Sci. 8 , $1-55$ (1986).

6. Nesbitt S. J. The early evolution of archosaurs: relationships and the origin of major clades. Bull. Am. Mus. Nat. Hist. 352, 1-292 (2011).

7. Ezcurra, M. D. The phylogenetic relationships of basal archosauromorphs, with an emphasis on the systematics of proterosuchian archosauriforms. PeerJ 4, e1778 (2016).

8. Nesbitt, S. J. et al. The earliest bird-line archosaurs and the assembly of the dinosaur body plan. Nature 544, 484-487 (2017).

9. Witmer, L. M., Chatterjee, S., Franzosa, J. \& Rowe, T. Neuroanatomy of flying reptiles and implications for flight, posture and behaviour. Nature 425, 950-953 (2003).

10. Wellnhofer, P. The Illustrated Encyclopedia of Pterosaurs (Salamander Books, 1991).

11. Witton, M. P. Pterosaurs: Natural History, Evolution, Anatomy (Princeton Univ. Press, 2013).

12. Dalla Vecchia, F. M. in Anatomy, Phylogeny and Palaeobiology of Early Archosaurs and their Kin (eds Nesbitt, S. J. et al) 119-155 (Geological Society London, 2013).

13. Britt, B. B. et al. Caelestiventus hanseni gen. et sp. nov. extends the desert-dwelling pterosaur record back 65 million years. Nat. Ecol. Evol. 2, 1386-1392 (2018).

14. Butler, R. J., Brusatte, S. L., Andres, B. \& Benson, R. B. How do geological sampling biases affect studies of morphological evolution in deep time? A case study of pterosaur (Reptilia: Archosauria) disparity. Evolution 66, 147-162 (2012)

15. Padian, K. Osteology and functional morphology of Dimorphodon macronyx (Buckland) (Pterosauria: Rhamphorhynchoidea) based on new material in the Yale Peabody Museum. Postilla 189, 1-44 (1983).

16. Benton, M. J. Classification and phylogeny of the diapsid reptiles. Zool. J. Linn. Soc. 84, 97-164 (1985).

17. Peters, D. A reexamination of four prolacertiforms with implications for pterosaur phylogenesis. Riv. Ital. Paleontol. Stratigr. 106, 293-336 (2000).

18. Bennett, S. C. Reassessment of the Triassic archosauriform Scleromochlus taylori: neither runner nor biped, but hopper. PeerJ 8, e8418 (2020).

19. Renesto, S. \& Binelli, G. Vallesaurus cenensis Wild 1991, a drepanosaurid (Reptilia, Diapsida) from the Late Triassic of northern Italy. Riv. Ital. Paleontol. Stratigr. 112, 77-94 (2006).

20. Langer, M. C., Nesbitt, S. J., Bittencourt, J. S. \& Irmis, R. B. in Anatomy, Phylogeny and Palaeobiology of Early Archosaurs and their Kin (eds Nesbitt, S. J. et al.) 156-186 (Geological Society London, 2013).

21. Cabreira, S. F. et al. A unique Late Triassic dinosauromorph assemblage reveals dinosaur ancestral anatomy and diet. Curr. Biol. 26, 3090-3095 (2016).

22. Kammerer, C. F., Nesbitt, S. J., Flynn, J. J., Ranivoharimanana, L. \& Wyss, A. R. A tiny ornithodiran archosaur from the Triassic of Madagascar and the role of miniaturization in dinosaur and pterosaur ancestry. Proc. Natl Acad. Sci. USA 117, 17932-17936 (2020).

23. Dalla Vecchia, F. M. Gli Pterosauri Triassici (Edizioni del Museo Friulano di Storia Naturale, 2014).

24. Dalla Vecchia, F. M. Seazzadactylus venieri gen. et sp. nov., a new pterosaur (Diapsida: Pterosauria) from the Upper Triassic (Norian) of northeastern Italy. PeerJ 7, e7363 (2019).

25. Codorniú, L., Paulina-Carabajal, A., Pol, D., Unwin, D. \& Rauhut, O. W. M. A Jurassic pterosaur from Patagonia and the origin of the pterodactyloid neurocranium. PeerJ $\mathbf{4}$, e2311 (2016)

26. Goloboff, P. A. \& Catalano, S. A. TNT version 1.5 , including a full implementation of phylogenetic morphometrics. Cladistics 32, 221-238 (2016).

27. Spoor, F. \& Zonneveld, F. Comparative review of the human bony labyrinth. Am. J. Phys. Anthropol. 107, 211-251 (1998).

28. Winship, I. R. \& Wylie, D. R. Zonal organization of the vestibulocerebellum in pigeons (Columba livia): I. Climbing fiber input to the flocculus. J. Comp. Neurol. 456, 127-139 (2003).

29. Birn-Jeffery, A. V., Miller, C. E., Naish, D., Rayfield, E. J. \& Hone, D. W. Pedal claw curvature in birds, lizards and mesozoic dinosaurs-complicated categories and compensating for mass-specific and phylogenetic control. PLoS ONE 7, e50555 (2012).

30. Kubo, T. \& Kubo, M. O. Associated evolution of bipedality and cursoriality among Triassic archosaurs: a phylogenetically controlled evaluation. Paleobiology 38, 474-485 (2012).

(c) The Author(s), under exclusive licence to Springer Nature Limited 2020 


\section{Methods}

\section{New phylogenetic definitions}

Pan-Aves Gauthier and de Queiroz, 2001 (this study), converted clade name

Registration number: 404 .

Phylogenetic definition. The most inclusive clade containing Vultur gryphus Linnaeus, 1758 (Aves), but not Crocodylus niloticus Laurenti, 1768 (Crocodylia). This is a crown-based total-clade definition.

Reference phylogeny. Phylogenetic hypothesis shown in Fig. 3 and Extended Data Fig. 4. Vultur gryphus nests within Dinosauria and C. niloticus within Pseudosuchia.

Composition. The composition is based on the reference phylogeny, Pan-Aves includes Aphanosauria ${ }^{8}$ and Ornithodira (see 'Ornithodira').

Ornithodira Gauthier, 1986 (this study), converted clade name

Registration number: 405.

Phylogenetic definition. The least inclusive clade containing Compsognathus longipes Wagner, 1859 (Dinosauria), and Pterodactylus (originally Ornithocephalus) antiquus Sömmerring, 1812 (Pterosauria), but not Alligator (originally Crocodilus) mississippiensis Daudin, 1802 (Crocodylia). This is a minimum clade definition.

Reference phylogeny. Phylogenetic hypothesis shown in Fig. 3 and Extended Data Fig. 4. Compsognathus longipes nests within Dinosauria, P. antiquus within Pterosauria and $A$. mississippiensis within Pseudosuchia.

Composition. The composition is based on the reference phylogeny, Ornithodira includes the main groups Lagerpetidae (see below), Pterosauria $^{31}$, Dinosauromorpha (see 'Dinosauromorpha') and possibly Scleromochlus taylori.

Lagerpetidae Arcucci, 1986 (this study), converted clade name Registration number: 406 .

Phylogenetic definition. The most inclusive clade containing Lagerpeton chanarensis Romer, 1971, but not Eudimorphodon ranzii Zambelli, 1973, Silesaurus opolensis Dzik, 2003, and V. gryphus Linnaeus, 1758. This is a maximum clade definition.

Reference phylogeny. Phylogenetic hypothesis shown in Fig. 3 and Extended Data Fig. 4.

Composition. The composition is based on the reference phylogeny, Lagerpetidae includes $L$. chanarensis, Ixalerpeton polesinensis, Kongonaphon kely and Dromomeron spp.

Dinosauromorpha Benton, 1985 (this study), converted clade name Registration number: 407.

Phylogenetic definition. The most inclusive clade containing $C$. longipes Wagner, 1859 (Dinosauria), but not $P$. antiquus Sömmerring, 1812 (Pterosauria), or A.mississippiensis Daudin, 1802 (Crocodylia). This is a maximum clade definition.

Reference phylogeny. Phylogenetic hypothesis shown in Fig. 3 and Extended Data Fig. 4. Compsognathus longipes nests within Dinosauria, P. antiquus within Pterosauria and $A$. mississippiensis within Pseudosuchia.

Composition. The composition is based on the reference phylogeny, Dinosauromorpha includes the main groups Silesauridae ${ }^{32,33}$ and Dinosauria ${ }^{34}$, including Aves ${ }^{35}$, plus some species level taxa such as Lagosuchus talampayensis.

Dinosauriformes Novas, 1992 (this study), converted clade name Registration number: 408 .

Phylogenetic definition. The least inclusive clade containing $C$. lon
Microcomputed tomography scans and digital processing

The partial lower jaw of Lagerpeton (PVL 4625) was scanned using X-ray microcomputed tomography at YPF TECNOLOGÍA (Y-TEC) using a Bruker Skyscan, the bones of Ixalerpeton (ULBRA-PVT059) were scanned at Centro para Documentação da Biodiversidade, Universidade de São Paulo using a Nanotom Scan machine (GE Sensing \& Inspection Technologies) and the braincase of $D$. gregorii (TMM 31100-1334) was scanned at the University of Texas High-Resolution X-ray CT Facility using a custom-built BIR scanner using a Feinfocus $X$-ray source and an Image Intensifier detector (further information about the scans is provided in the Supplementary Information). The images of Lagerpeton were processed using the software 3D Slicer version $4.7^{36}$ and the images of Ixalerpeton and Dromomeron were processed using the software Amira (version 5.3.3, Visage Imaging).

\section{Morphogeometric sampling of the endosseous labyrinth of the} inner ear

The course of each semicircular canal of the inner ear was quantitatively sampled in available taxa using sliding three-dimensional semilandmarks (on left labyrinths or reflected right labyrinths). A midline skeleton of each canal was generated using the 'autoskeleton' function of Avizo 9 (https://www.fei.com/software/amira-avizo/), which represents the mean endolymph flow path through a semicircular canal ${ }^{37}$. The landmarking of midline skeletons captures the relative lengths, orientations and morphology of the canals. Open semilandmark curves started at the intersection of the canal with its ampulla, ending at its intersection with the common crus. These start and end points represent six fixed, single-point landmarks. The posterior ampulla was estimated to be the ventralmost point on the trajectory of the posterior semicircular canal (psc), and the intersection of the lateral semicircular canal (Isc) with the common crus was estimated to be directly ventral to the intersection of the psc with the common crus ${ }^{38}$. In addition, a closed loop of semilandmarks was placed around the inner surface of the anterior semicircular canal (asc) to capture variation in relative canal thickness ${ }^{39}$. This landmarking procedure involved placing arbitrary numbers of points in each semilandmark series. Thus, these series were resampled to equal numbers of points in each specimen using the digit.curves function of the package Geomorph (version 3.2.1) ${ }^{40}$ written for $\mathrm{R}$ (version 3.6.0) ${ }^{41}$ : asc midline skeleton (9 points), psc midline skeleton ( 8 points), lsc midline skeleton (10 points) and asc inner loop (13 points). Landmark configurations were transformed through a generalized Procrustes superimposition using the gpagen function of Geomorph in R. This procedure removes differences in orientation and position of specimens and separates overall size information (centroid size) from shape information. Semilandmarks were allowed to slide along their curves during superimposition to minimize bending energy difference from the mean shape.

\section{Principal component analysis}

We conducted principal component analyses of our geometric morphometric dataset using the plotTangentSpace() function of the $\mathrm{R}$ package Geomorph (version 3.2.1) ${ }^{40}$.

\section{Phylogenetic analyses}

Maximum parsimony analysis. The phylogenetic relationships of pterosaurs and lagerpetids were analysed using the data matrix of 
In addition, the formulation or wording was modified or additional states were added for 76 characters, and several scorings were changed with respect to previous versions of the matrix (Supplementary Information). Character 119 was excluded before the searches following a previously published study ${ }^{43}$. Because they represent nested sets of homologies, the following characters were considered additive: 1,2 , $7,10,17,19-21,28,29,36,40,42,46,50,54,66,71,74-76,122,127,146$, $153,156,157,171,176,177,187,202,221,227,263,266,278,279,283,324$, $327,331,337,345,351,352,354,361,365,370,377,379,386,387,398$, $410,414,424,430,435,446,448,454,455,458,460,463,470,472,478$ $482,483,485,489,490,502,504,510,516,521,529,537,546,552,556$ $557,567,569,571,574,581,582,588,636,648,652,662,701,731,735$ $737,738,743,749,766,784$ and 816 . Several terminal taxa were also excluded because they were originally scored only with the purpose of conducting morphological disparity analyses and were not intended to be included, yet, in phylogenetic analyses ${ }^{44}$. The final data matrix is composed of 822 active characters and 157 active taxa. A second analysis was conducted including S. taylori, resulting in a total of 158 taxa. Interpretation of detailed anatomical features is extremely difficult for this species, owing to the preservation of all its specimens as natural moulds of very small-sized bones in a coarse sandstone ${ }^{4}$. Thus, we decided to not include this taxon in the first analysis, because this could introduce a subtantial amount of scoring errors.

The data matrix was analysed under equally weighted maximum parsimony using TNT $1.5^{26}$. The search strategies started using a combination of the tree-search algorithms Wagner trees, tree bisection and reconnection (TBR) branch swapping, sectorial searches, Ratchet and tree fusing, until 100 hits of the same minimum tree length were achieved. The best trees obtained were subjected to a final round of TBR branch swapping. Zero-length branches in any of the recovered most-parsimonious trees were collapsed. Branch support was quantified using Bremer support values and a bootstrap resampling analysis, using 1,000 technical pseudo-replicates and reporting both absolute and GC (group present/contradicted) frequencies. The minimum number of additional steps necessary to generate alternative, suboptimal topologies was calculated when constraining the position of pterosaurs and lagerpetids in different parts of the tree or constraining the topology of pterosaur interrelationships found by previous studies and rerunning the analyses.

An alternative analysis was conducted using the three-dimensional morphogeometric configuration of the endosseous labyrinth of the inner ear. The aligned (Procrustes) coordinates were exported to TNT 1.5 and they were used as a single morphogeometric continuous character $^{26}$. The configurations were realigned in TNT by applying the minimum distances criterion ${ }^{26}$ and using Trilophosaurus buettneri as the reference taxon because it has been recovered as the earliest branching terminal taxon, among those with three-dimensionally sampled endosseous labyrinths, in previous analyses of this dataset ${ }^{7,42,43}$. As a secondary analysis, we used another early branching archosauromorph, Mesosuchus browni, as the reference taxon to test changes in the topologies. The discrete characters of the inner ear (characters 729-743) were excluded during the searches using the three-dimensional morphogeometric character because of their non-independence. The search strategy started using 10 technical replicates of Wagner trees followed by the TBR branch-swapping algorithm (holding 10 trees per replication). The best trees obtained were subjected to a final round of TBR branch swapping. Zero-length branches and additive characters appearance dates for all tips of the tree. We implemented a node age calibration for Archosauria with a uniform prior of 249.2-257.3 million years ago, in which the minimum is informed by the ages of the oldest archosaurian specimens ${ }^{44}$, and the maximum by age estimates for the crocodile-lizard split ${ }^{46}$. We specified a fossilized birth-death process as the tree model using standard parameterizations and values. Fossils were specified to be tips. The deepest split within the tree was parameterized with a uniform (303.4-318.0 million years ago) tree age prior, for which the maximum is based on the age of the Joggins Formation, which documents the earliest crown-amniotes ${ }^{47}$ and the minimum is based on the chronostratigraphic uncertainty of $P$. kansensis, the outgroup and oldest taxon of our sample. We used metropolis-coupling Markov chain Monte Carlo algorithms with two independent runs of four chains, using a heating coefficient of 0.05 and 3 swap attempts per generation. Topological convergence, indicated by average standard deviation of split frequencies decreasing below 0.01 , was achieved after $23,496,000$ generations. Potential scale reduction factors of 1.0, visual inspection of trace plot with Tracer (version 1.7.1) ${ }^{48}$ and estimated sample sizes (ESS) for all parameters $>200$ further indicated convergence. An additional analysis was performed with the same settings, except that the topology was constrained to investigate topological effects on evolutionary rates. The topology is constrained to follow the topology of one of the most-parsimonious trees of the maximum-parsimony analysis after constraining lagerpetids to be dinosauromorphs. This analysis was specified to run for $24,000,000$ generations and estimated sample sizes $>200$ indicated convergence. Additional phylogenetic analysis details are provided in the Supplementary Information.

\section{Reporting summary}

Further information on research design is available in the Nature Research Reporting Summary linked to this paper.

\section{Data availability}

The data matrices for the phylogenetic analyses in NEXUS and/or TNT formats have been deposited in MorphoBank at http://morphobank. org/permalink/?P3773. Three-dimensional models of lagerpetid bones in STL format are available in MorphoSource at http://www.morphosource.org/Detail/ProjectDetail/Show/project_id/1095 under the following DOIs: https://doi.org/10.17602/M2/M157269, https://doi. org/10.17602/M2/M157271, https://doi.org/10.17602/M2/M157273, https://doi.org/10.17602/M2/M157275, https://doi.org/10.17602/ M2/M157280, https://doi.org/10.17602/M2/M157282, https://doi. org/10.17602/M2/M157283 and https://doi.org/10.17602/M2/M157284. Source data are provided with this paper.

31. Andres, B. \& Padian, K. in Phylonyms: A Companion to the PhyloCode (eds de Queiroz, K. et al.) 1201-1204 (CRC, 2020)

32. Langer, M. C., Ezcurra, M. D., Bittencourt, J. S. \& Novas, F. E. The origin and early evolution of dinosaurs. Biol. Rev. Camb. Philos. Soc. 85, 55-110 (2010).

33. Nesbitt, S. J. et al. Ecologically distinct dinosaurian sister group shows early diversification of Ornithodira. Nature 464, 95-98 (2010).

34. Langer, M. C., Novas, F. E., Bittencourt, J., Ezcurra, M. D. \& Gauthier, J. A. in Phylonyms: A Companion to the PhyloCode (eds de Queiroz, K. et al.) 1209-1217 (CRC, 2020).

35. Clarke, J. A. et al. in Phylonyms: A Companion to the PhyloCode (eds de Queiroz, K. et al.) 1247-1253 (CRC, 2020).

36. Fedorov, A. et al. 3D Slicer as an image computing platform for the quantitative imaging network. Magn. Reson. Imaging 30, 1323-1341 (2012).

37. David, R. et al. Motion from the past. A new method to infer vestibular capacities of extinct species. C. R. Palevol 9. 397-410 (2010). 
42. Butler, R. J., Ezcurra, M. D., Liu, J., Sookias, R. B. \& Sullivan, C. The anatomy and phylogenetic position of the erythrosuchid archosauriform Guchengosuchus shiguaiensis from the earliest Middle Triassic of China. PeerJ 7, e6435 (2019).

43. Ezcurra, M. D. et al. Deep faunistic turnovers preceded the rise of dinosaurs in southwestern Pangaea. Nat. Ecol. Evol. 1, 1477-1483 (2017).

44. Ezcurra, M. D. \& Butler, R. J. The rise of the ruling reptiles and ecosystem recovery from the Permo-Triassic mass extinction. Proc. R. Soc. Lond. B 285, 20180361 (2018)

45. Ronquist, $F$, van der Mark, P. \& Huelsenbeck, J. P. in The Phylogenetic Handbook: a Practical Approach to Phylogenetic Analysis and Hypothesis Testing (eds Lemey, P. et al) 210-266 (Cambridge Univ. Press, 2009).

46. Ezcurra, M. D., Scheyer, T. M. \& Butler, R. J. The origin and early evolution of Sauria: reassessing the Permian saurian fossil record and the timing of the crocodile-lizard divergence. PLOS ONE 9, e89165 (2014).

47. Benton, M. J. et al. Constraints on the timescale of animal evolutionary history. Palaeontol. Electronica 18, 1-106 (2015)

48. Rambaut, A., Drummond, A. J., Xie, D., Baele, G. \& Suchard, M. A. Posterior summarization in Bayesian phylogenetics using Tracer 1.7. Syst. Biol. 67, 901-904 (2018).

Acknowledgements We thank C. Alsina and F. De Cianni (MACN) for repreparation, M. B. Epele and $\mathrm{M}$. Cipollone for $\mu \mathrm{CT}$ scanning and F. Tricárico for scanning-electron microscopy

microphotographs of PVL 4625; M. Colbert for $\mu$ CT scanning TMM 31100-1334; D. Cavallari for $\mu C T$ scanning ULBRA-PVTO59; V. Radermacher and J. Choiniere for providing access to the
$\mu C T$ scan of a Heterodontosaurus specimen scanned at ESRF, and ESI and SAHRA for permits for that work; A. Paulina-Carabajal for allowing access to the $\mu$ CT scan of Allkaruen,

S. Chapman, H. Furrer, Z. Gasparini, M. Moser, G. Muscio, P. Ortíz, A. Paganoni, J. Powell,

O. Rauhut, E. Ruigómez, R. Stecher and A. Tintori for access to specimens; J. Gauthier for

- discussion and suggestions about phylogenetic nomenclature; D. Boyer for assisting us during the uploading of the three-dimensional models of specimens to MorphoSource:
S. Hartman allowed the use and modification of the lagerpetid skeletal reconstruction; and S. Brusatte and N. Fraser for comments that improved the overall quality of the manuscript. R. Nogueira digitally assembled and reconstructed the lagerpetid skull and created the life reconstruction. University of Antananarivo, Madagascar, allowed access to three-dimensional data and first-hand study of Kongonaphon. This study was supported by the Sepkoski Grant of the Paleontological Society (to M.D.E.), Agencia Nacional de Promoción Científica y Técnica (PICT 2018-01186; to M.D.E.), The Coleman and Susan Burke Foundation (to F.E.N) Financiadora de Estudos e Projetos, Brazilian Federal Government (project CT-INFRA 01/2013), and São Paulo Research Foundation (FAPESP 2014/03825-3 to M.C.L. and 2018/18145-9 to M.B.).

Author contributions M.D.E., S.J.N. and M.C.L. designed the project: M.D.E. S.J.N. M.B., F.L.A A.G.M. and M.C.L. described the material; M.B., R.B.J.B., S.W.E. and A.R.G. processed and sampled CT and $\mu$ CT data; M.D.E., S.J.N., M.B., F.L.A., F.M.D.V., S.W.E., N.D.S. and M.C.L. scored phylogenetic matrices; M.D.E. conducted the maximum-parsimony analyses; R.B.J.B. and S.W.E. conducted the Bayesian analyses; M.D.E., S.J.N., M.B. and M.C.L. wrote the bulk of the manuscript; M.D.E., S.J.N., M.B., F.M.D.V. and S.W.E. made figures; all authors collected data and contributed to the writing, discussion and conclusion.

Competing interests The authors declare no competing interests.

\section{Additional information}

Supplementary information is available for this paper at https://doi.org/10.1038/s41586-020 3011-4.

Correspondence and requests for materials should be addressed to M.D.E.

Peer review information Nature thanks Stephen Brusatte, Nicholas Fraser and the other, anonymous, reviewer(s) for their contribution to the peer review of this work. Peer reviewer reports are available.

Reprints and permissions information is available at http://www.nature.com/reprints. 


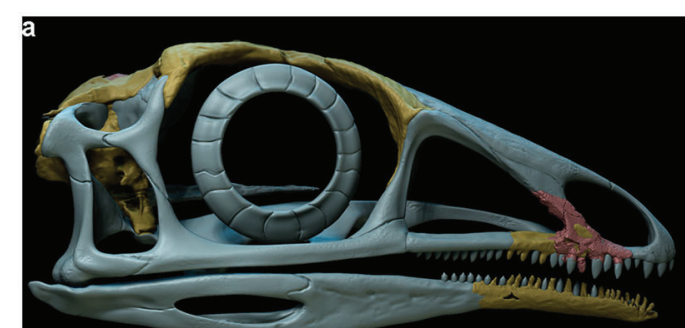

6
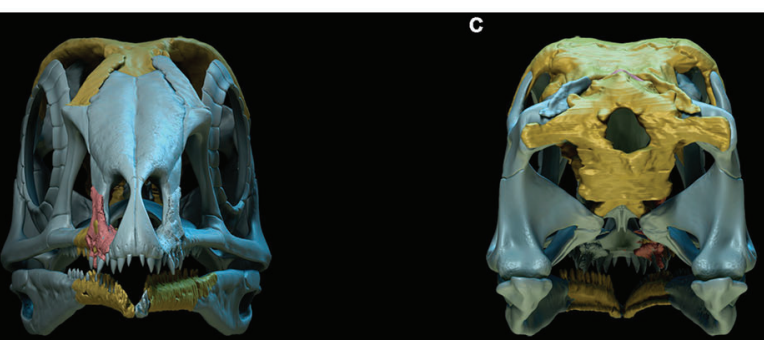

d

e
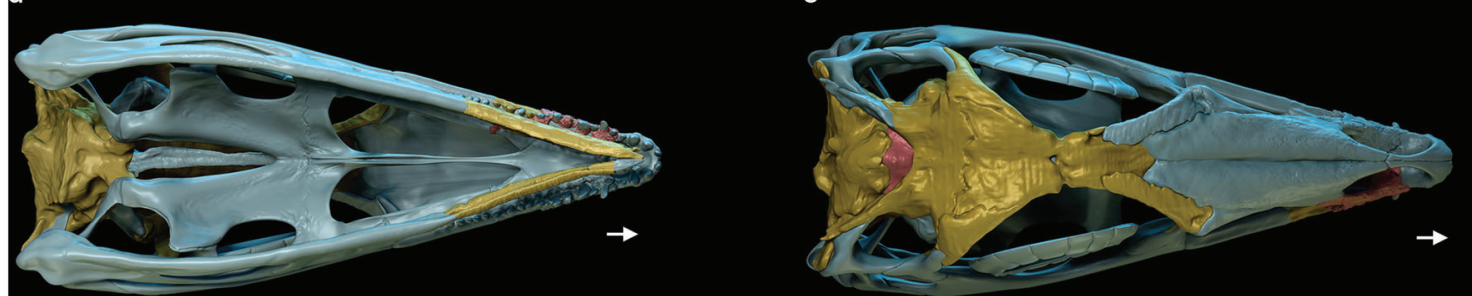

g
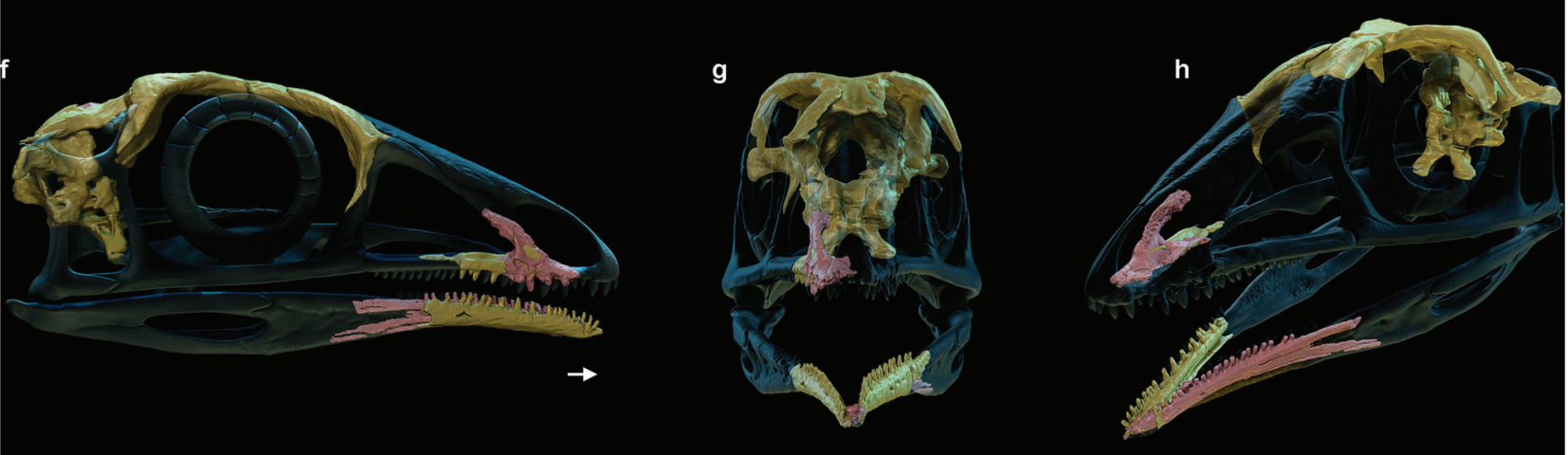

7

-

美

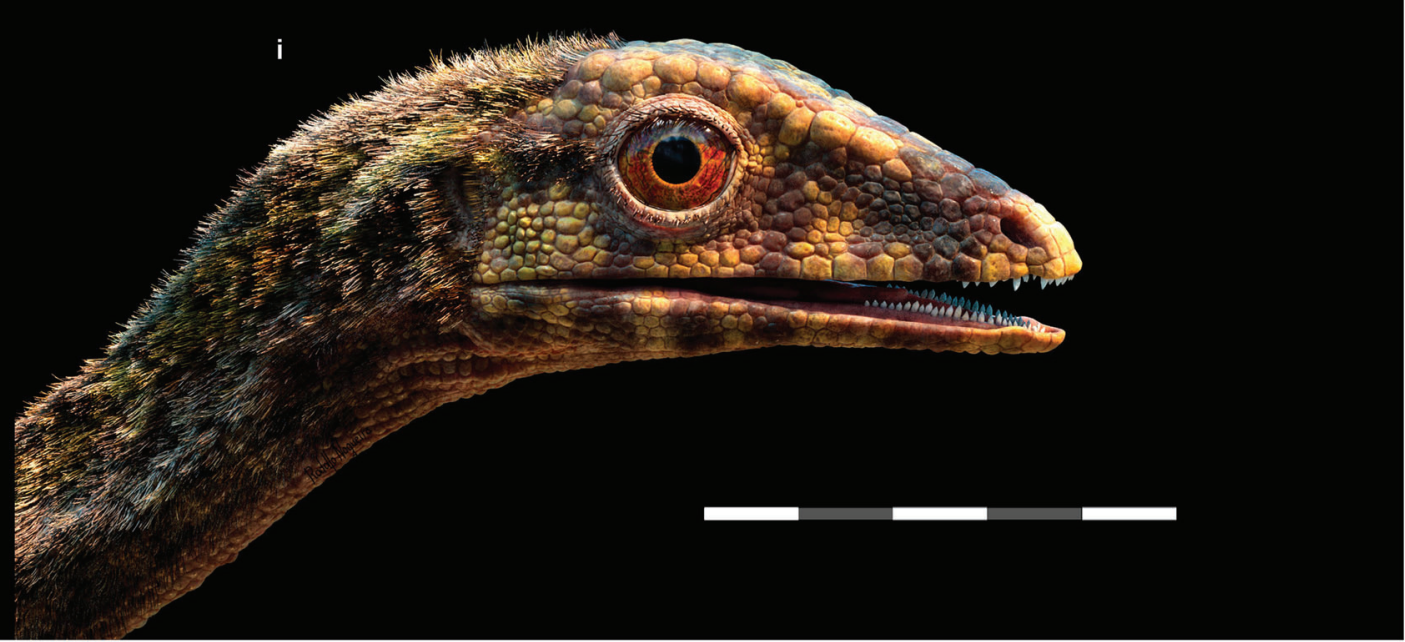

Extended Data Fig. 1 | Life reconstruction and three-dimensional reconstruction of the skull of the lagerpetid $I$. polesinensis (ULBRA-PVT059, holotype) with additions of cranial bones of other lagerpetids. a-i, Images are shown in right lateral (a, f, i), anterior $(\mathbf{b}, \mathbf{g})$, posterior (c), ventral (d), dorsal (e) and anterodorsolateral (h) views. roof bones through them. Bones of $I$. polesinensis are indicated in yellow and those of $K$. kely (UA 10618, holotype), D. gregorii (TMM31100-1334, referred specimen) and $L$. chanarensis (PVL 4625, referred specimen) in red, and inferred bones in light blue. Arrows indicate the anterior direction. Complete scale bar, $5 \mathrm{~cm}$. Life and skull reconstruction by R. Nogueira. 


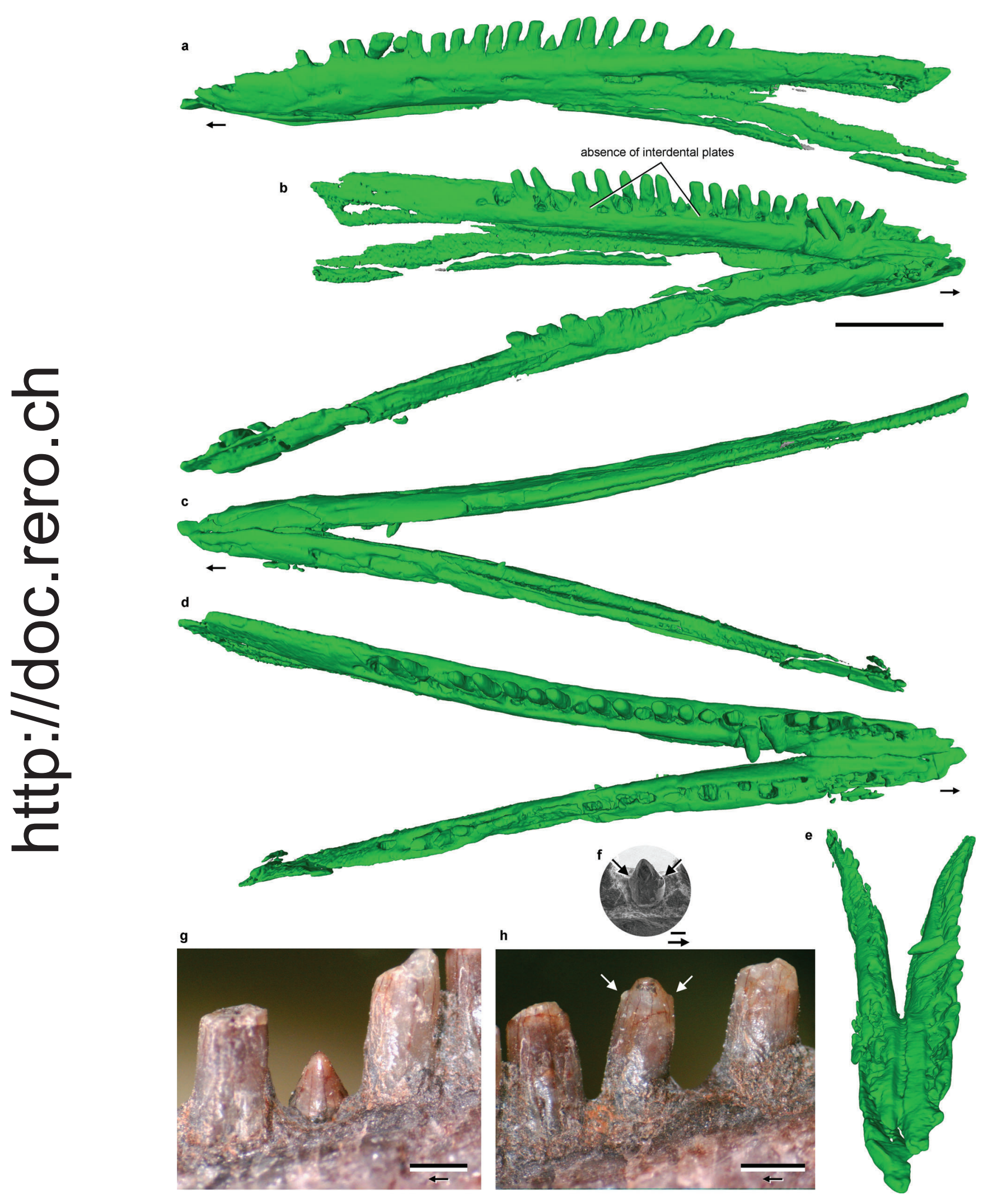




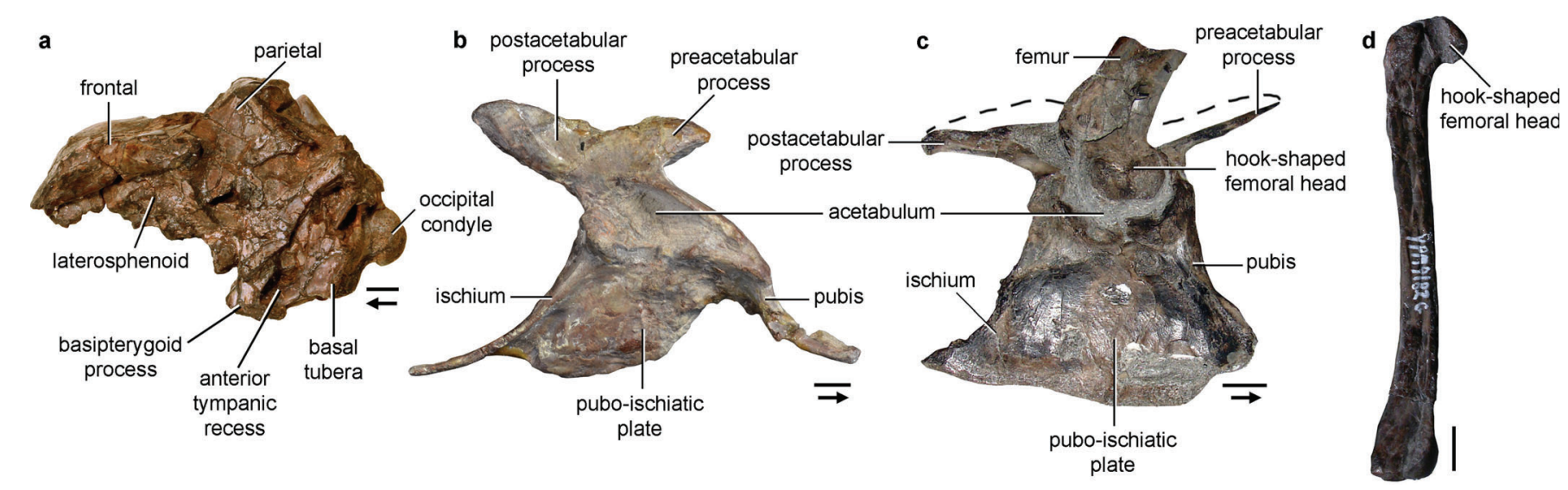

Extended Data Fig. 3 | Additional images and comparisons between lagerpetids and pterosaurs. a, Partial skull roof and braincase of the lagerpetid D. gregorii (TMM 31100-1334) in left lateral view. b, Right hemipelvis of the lagerpetid L.chanarensis (PVL 4619) in lateral view. c, Left hemipelvis and articulated proximal end of femur of the pterosaur Dimorphodon macronyx (NHMUK PV OR 41212, reversed) in lateral view. d, Right femur of the pterosaur D. macronyx (YPM 9182) in anterolateral view. Arrows indicate the anterior direction. Scale bars, $3 \mathrm{~mm}(\mathbf{a})$ and $5 \mathrm{~mm}(\mathbf{b}-\mathbf{d})$. 


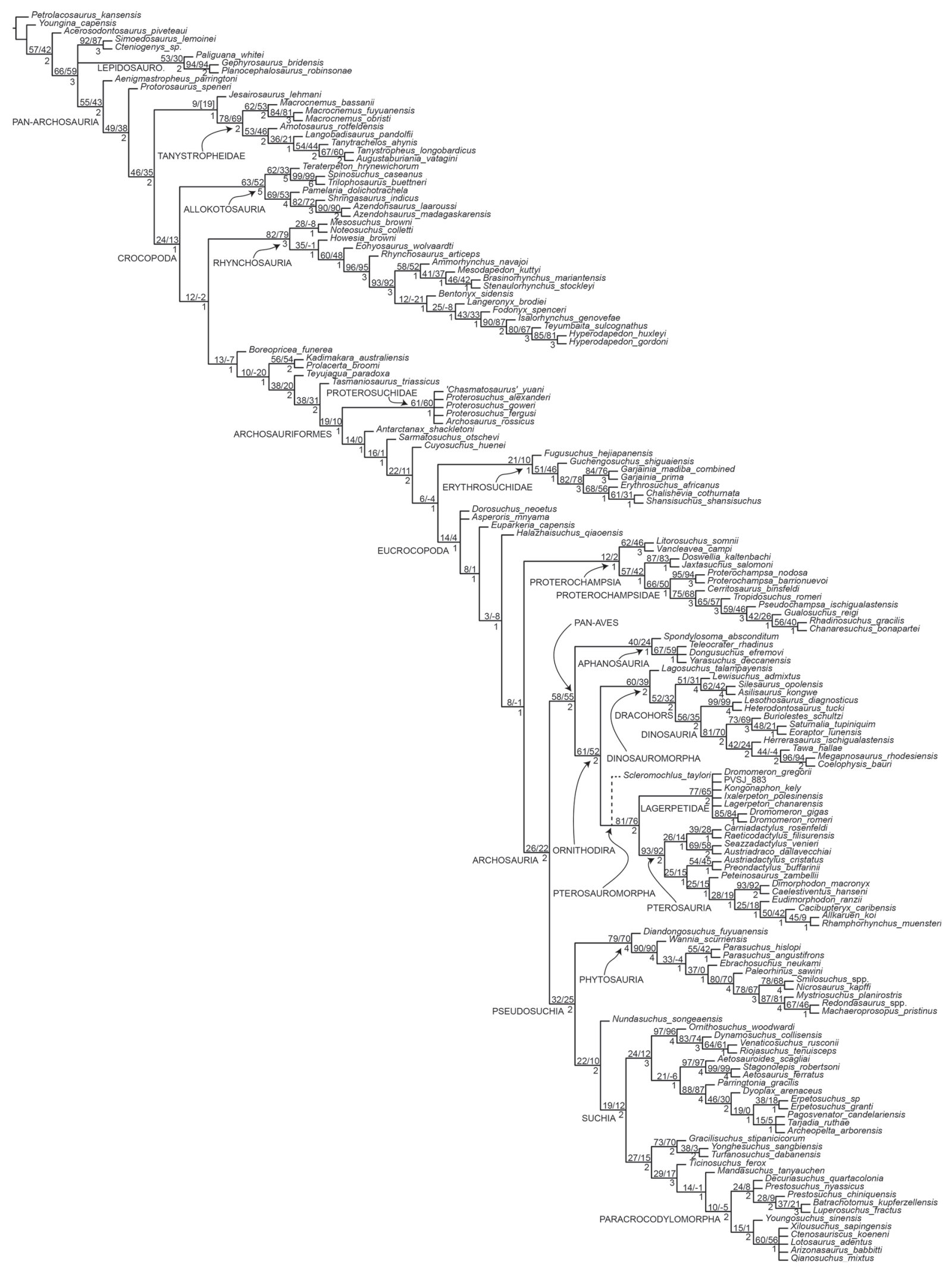




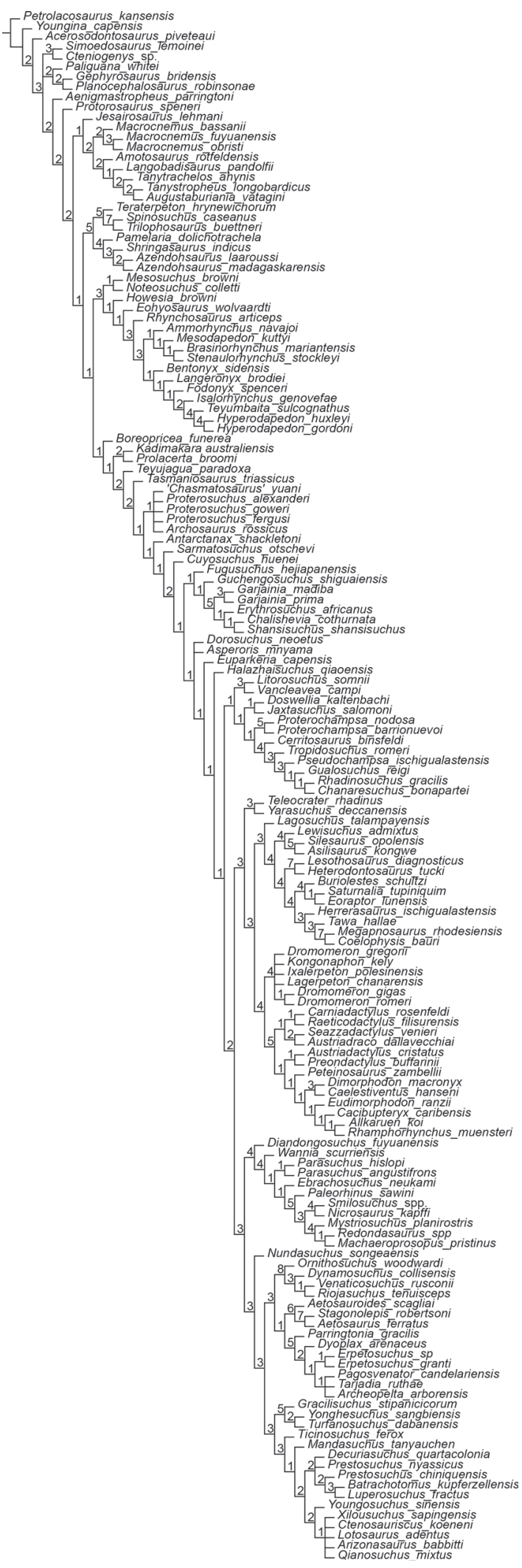




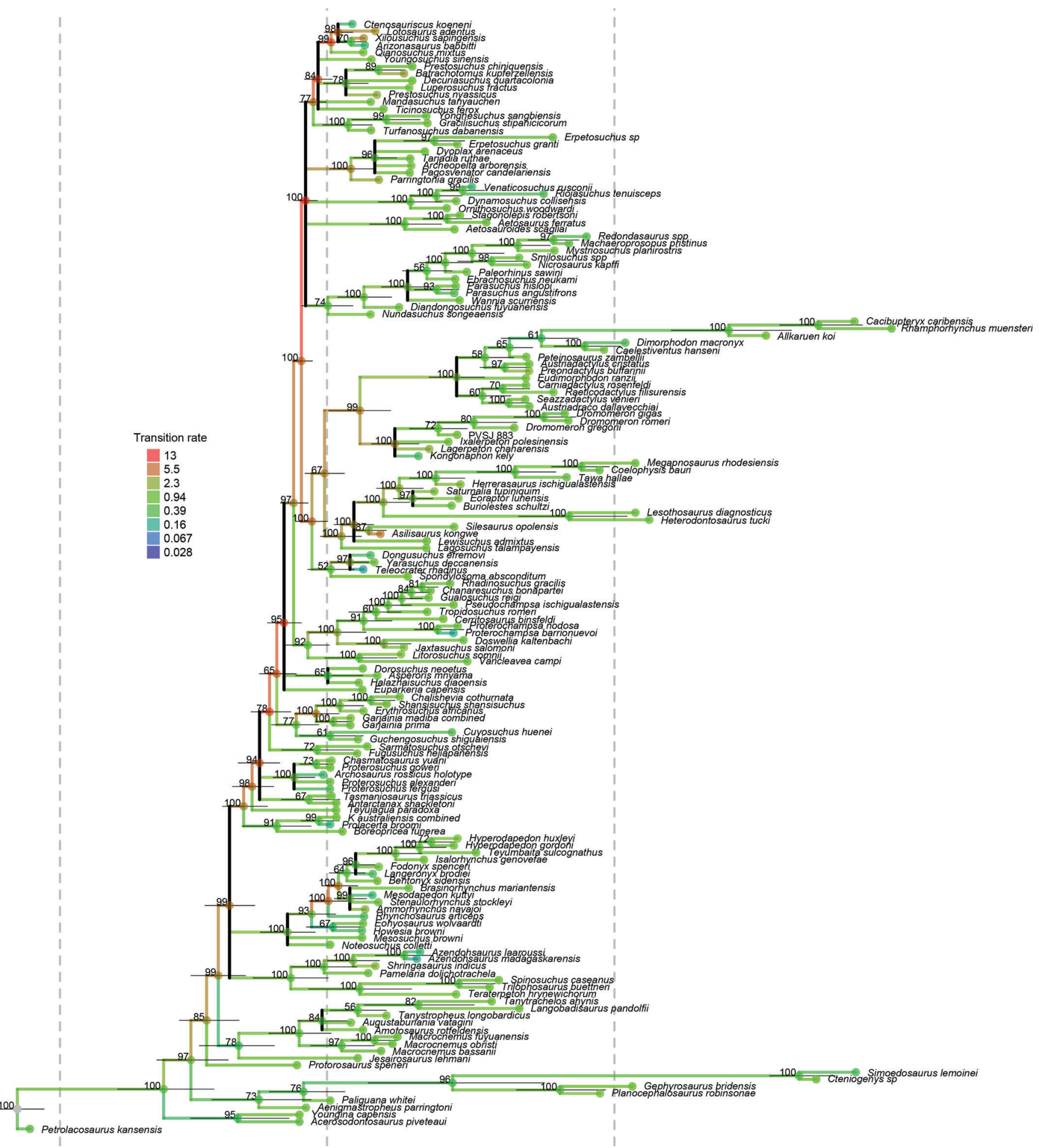

Extended Data Fig. 6 | Majority rule tree recovered from the unconstrained Bayesian phylogenetic analysis. Branch colours indicate character state transition rates (that is, the evolutionary rates), numbers at the nodes indicate posterior probabilities, the thin black horizontal line segments indicate the
95\% probability distribution of node ages, and dotted vertical lines indicate the boundaries between the Carboniferous, Permian, Triassic and Jurassic geological periods. Thick black vertical bars indicate polytomies and, as a result, transition rates could not be calculated. 


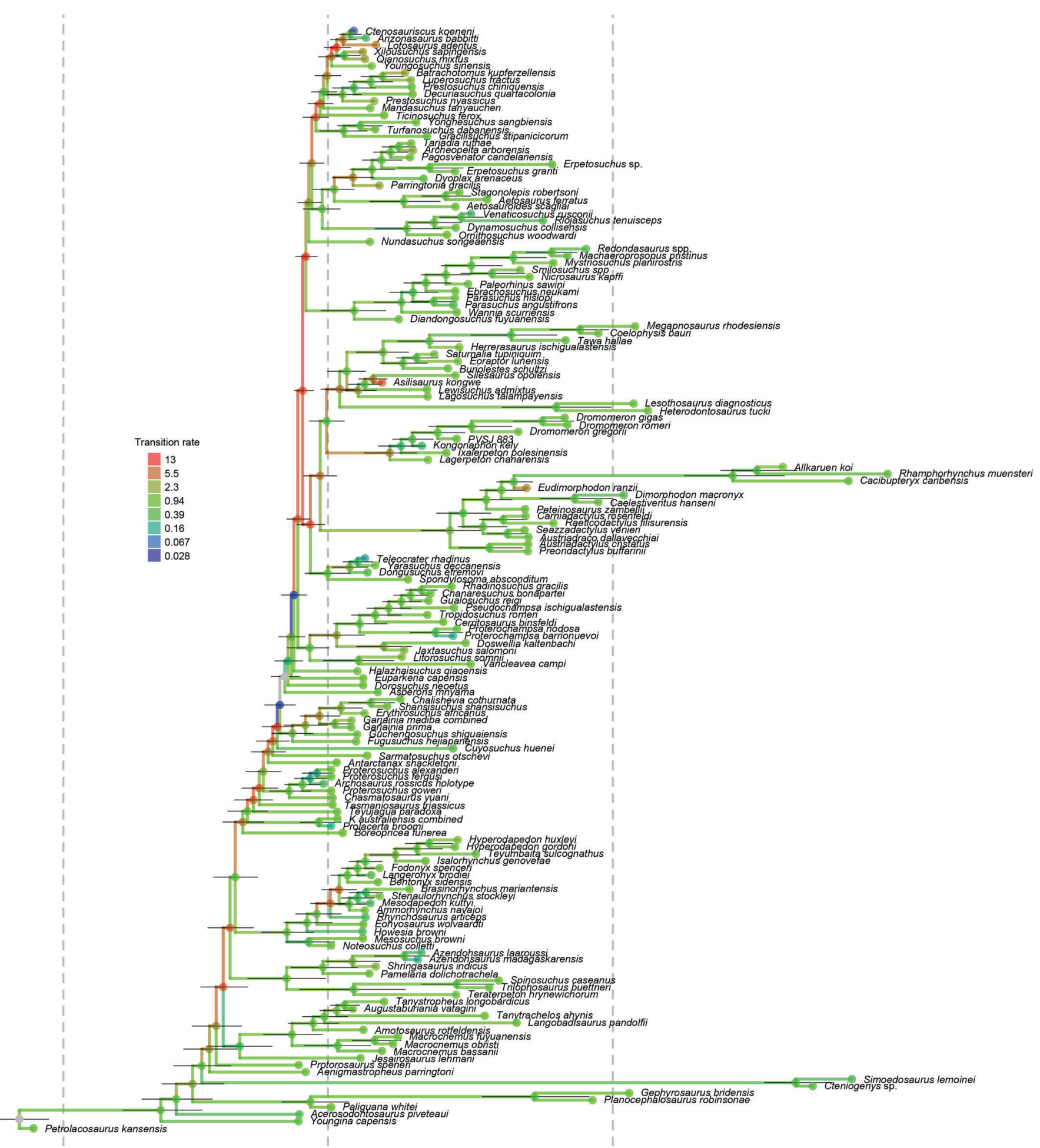

Extended Data Fig. 7| Majority rule tree recovered from the constrained Bayesian phylogenetic analysis. The topology of this tree has been constrained a priori after selecting randomly one of the most-parsimonious trees recovered after forcing the position of lagerpetids as the earliest branching dinosauromorphs in the maximum parsimony analysis. Branch colours indicate character state transition rates, the black horizontal line segments indicate the $95 \%$ probability distribution of node ages and the dotted vertical lines indicate the boundaries between the Carboniferous, Permian, Triassic and Jurassic geological periods. Posterior probabilities at the nodes are not shown because the topology is fully constrained. 


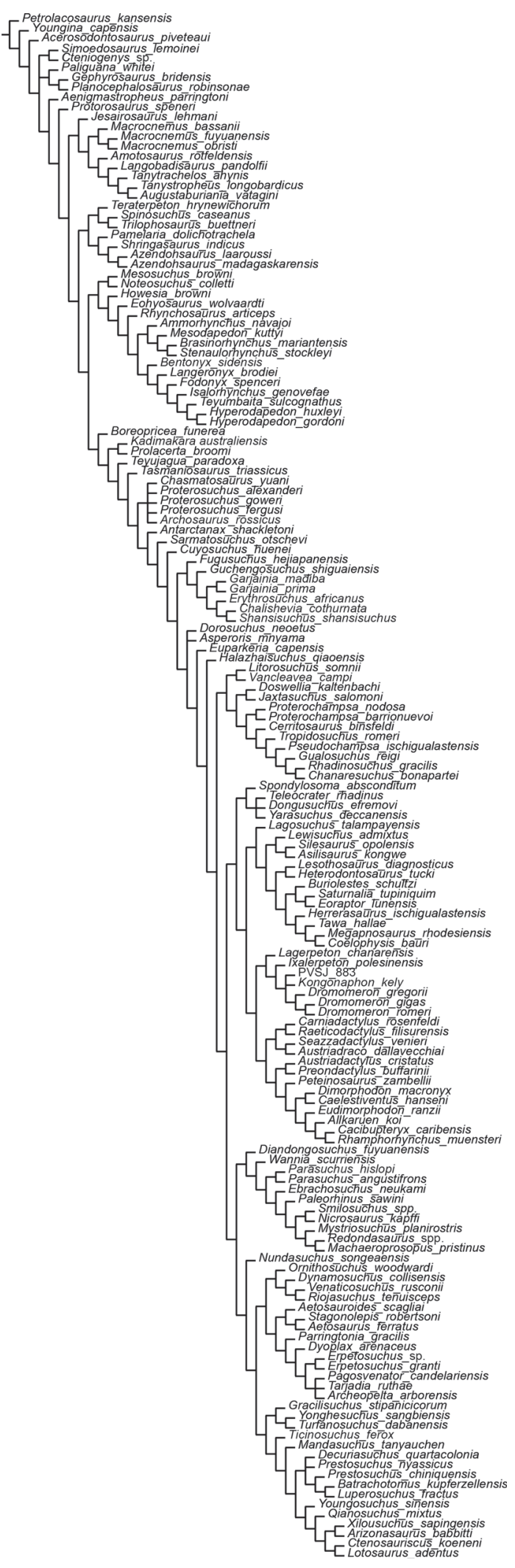


a

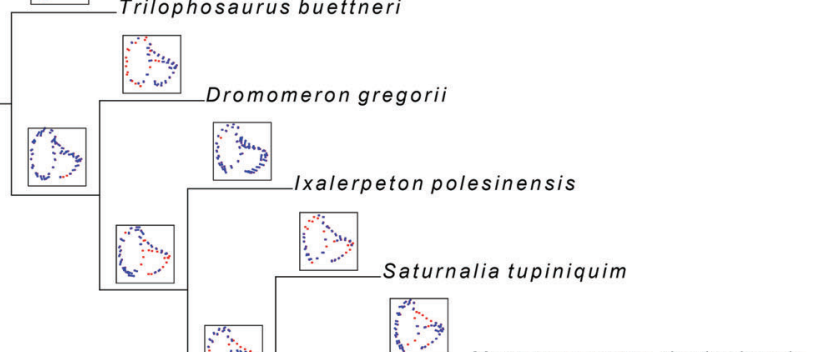

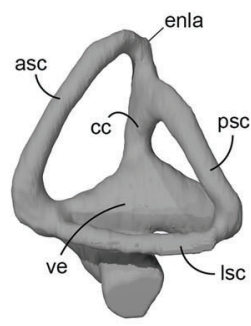

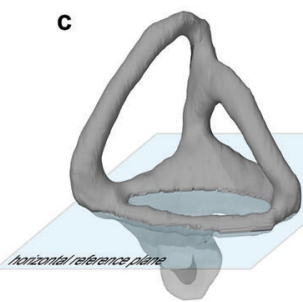

d

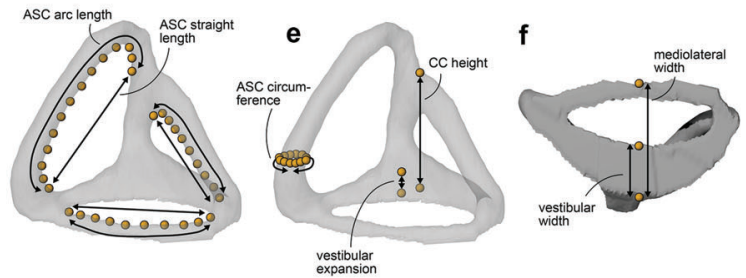

expension Megapnosaurus rhodesiensis
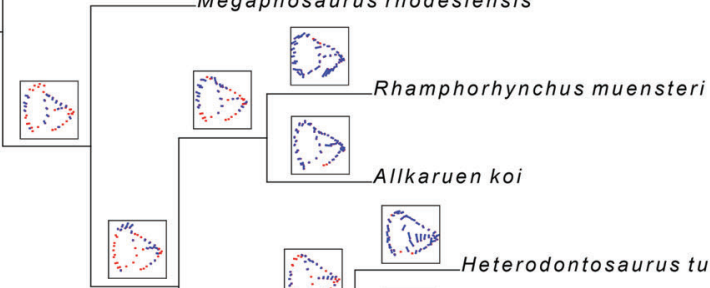

g

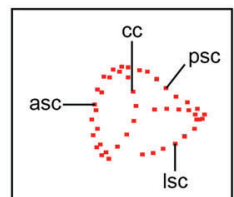

Extended Data Fig. 9| Single most-parsimonious tree found when analysing only the three-dimensional morphogeometric configuration of the inner ear and three-dimensional examples of how distances and angles were measured in the three-dimensional endosseous labyrinth models. a, Tree rooted with T.buettneri.b, Three-dimensional model of the left

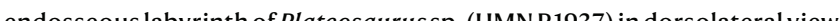

scheme for semicircular canal length measurements. e, Landmark scheme for asc circumference and labyrinth height measurements. f, Landmark scheme for labyrinth width measurements in ventral view on the reference plane. g, Landmark constellation explanation. asc, anterior semicircular canal; cc, common crus; enla, endosseous labyrinth; Isc, lateral semicircular canal; psc, 


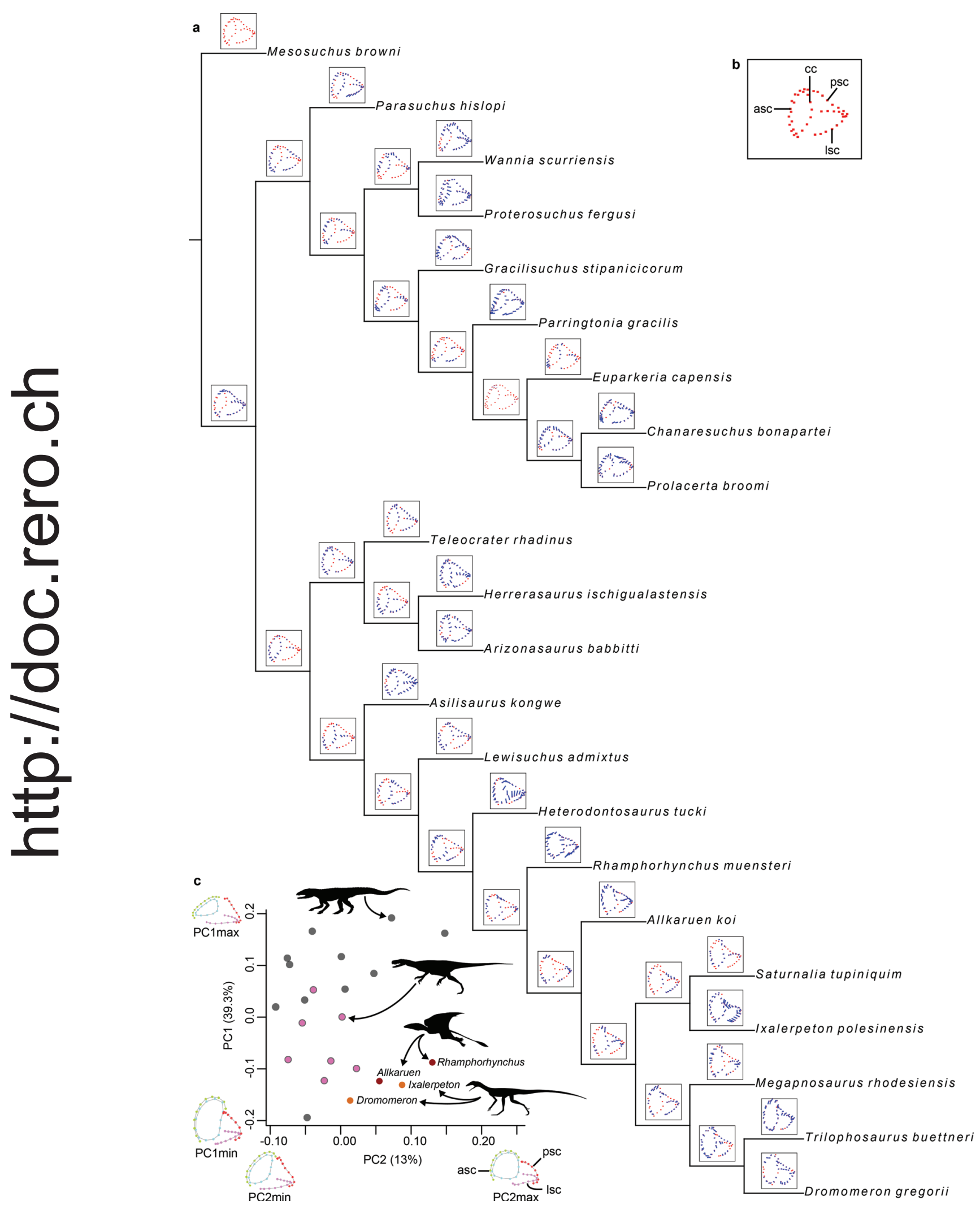

18 


\section{ature research}

Corresponding author(s): Martín D. Ezcurra

Last updated by author(s): Sep 16, 2020

\section{porting Summary}

e Research wishes to improve the reproducibility of the work that we publish. This form provides structure for consistency and transparency sorting. For further information on Nature Research policies, see our Editorial Policies and the Editorial Policy Checklist.

\section{tistics}

II statistical analyses, confirm that the following items are present in the figure legend, table legend, main text, or Methods section.

Confirmed

$叉$ The exact sample size $(n)$ for each experimental group/condition, given as a discrete number and unit of measurement

A statement on whether measurements were taken from distinct samples or whether the same sample was measured repeatedly

The statistical test(s) used AND whether they are one- or two-sided

Only common tests should be described solely by name; describe more complex techniques in the Methods section.

A description of all covariates tested

A description of any assumptions or corrections, such as tests of normality and adjustment for multiple comparisons

A full description of the statistical parameters including central tendency (e.g. means) or other basic estimates (e.g. regression coefficient)

AND variation (e.g. standard deviation) or associated estimates of uncertainty (e.g. confidence intervals)

For null hypothesis testing, the test statistic (e.g. $F, t, r$ ) with confidence intervals, effect sizes, degrees of freedom and $P$ value noted

Give $P$ values as exact values whenever suitable.

For Bayesian analysis, information on the choice of priors and Markov chain Monte Carlo settings

For hierarchical and complex designs, identification of the appropriate level for tests and full reporting of outcomes

Estimates of effect sizes (e.g. Cohen's $d$, Pearson's $r$ ), indicating how they were calculated

Our web collection on statistics for biologists contains articles on many of the points above.

tware and code

/ information about availability of computer code

a collection 3D Slicer version 4.7, Amira version 5.3.3; Avizo lite 9.2 (autokeleton function); Geomorph version 3.2.1 package for R.

:a analysis TNT version 1.5; MrBayes 3.2.6; Tracer 1.7.1; Geomorph version 3.2.1 package for $\mathrm{R}$.

Inuscripts utilizing custom algorithms or software that are central to the research but not yet described in published literature, software must be made available to editors and ers. We strongly encourage code deposition in a community repository (e.g. GitHub). See the Nature Research guidelines for submitting code \& software for further information.

a

I information about availability of data

nanuscripts must include a data availability statement. This statement should provide the following information, where applicable:

Accession codes, unique identifiers, or web links for publicly available datasets

A list of figures that have associated raw data

A description of any restrictions on data availability

ssil specimens used for this study are deposited in public institutions available for qualified researchers upon request. The data matrices for the phylogenetic ses have been deposited in MorphoBank (http://morphobank.org/permalink/?P3773) and the mCT-scan based 3D models of the lagerpetid cranial bones have deposited in MorphoSource (http://www.morphosource.org/Detail/ProiectDetail/Show/proiect id/1095). 


\section{Id-specific reporting}

e select the one below that is the best fit for your research. If you are not sure, read the appropriate sections before making your selection.
fe sciences
Behavioural \& social sciences
Ecological, evolutionary \& environmental sciences

eference copy of the document with all sections, see nature.com/documents/nr-reporting-summary-flat.pdf

\section{e sciences study design}

ıdies must disclose on these points even when the disclosure is negative.

nple size $\quad$ Our study considers all available specimens of the studied species and the phylogenetic analyses include the so far most comprehensive sample of Permo-Triassic archosauromorph species. Terminals of the phylogenetic data matrices were scored based on the type specimens and all available, unambiguously referred specimens.

a exclusions The taxonomic and character samples of the phylogenetic analyses were intended to be as broad as possible, without exclusions.

lication

Our taxon-character matrix is the latest modification of that originally published by Ezcurra (2016 - PeerJ), all modifications are described in detail in the supplementary information. This documentation and accessibility of the data matrices allow the replication of the analyses. The matrix of Ezcurra (2016) has been reanalyzed independently several times (>10 analyses) in the last four years and all replication attempts were successful (with exception of minor changes as a result of slight modifications and/or expansions of the dataset).

domization Our study has used all unambiguously referred specimens and in most cases not more than five individuals are available. Thus, no randomizations were required.

The taxon-character matrices for the phylogenetic analyses were built on the basis of independent observation of each taxon. Blinding was not necessary, neither possible, because we have used all available specimens for the scoring of characters in each sampled species.

quire information from authors about some types of materials, experimental systems and methods used in many studies. Here, indicate whether each material, n or method listed is relevant to your study. If you are not sure if a list item applies to your research, read the appropriate section before selecting a response.

:erials \& experimental systems

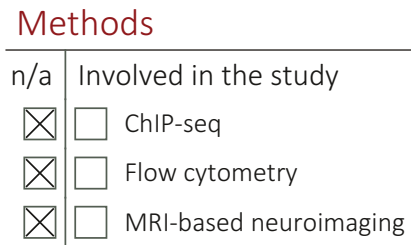

$\bigotimes$ Palaeontology and archaeology

X MRI-based neuroimaging

Animals and other organisms

Human research participants

Clinical data

Dual use research of concern

\section{zeontology and Archaeology}

cimen provenance

:cimen deposition

ing methods
The most relevant specimens for our study have been collected during previous research efforts and fieldworks in the Upper Triassic Chañares Formation, Ischigualasto-Villa Unión Basin, Argentina (Lagerpeton chanarensis); Upper Triassic Santa Maria Sequence, Paraná Basin, Brazil (Ixalerpeton polesinensis), Upper Triassic Chinle Formation and Dockum Group, USA (Dromomeron romeri and Dromomeron gregorii), and Middle-Upper Triassic Isalo II beds, Madagascar (Kongonaphon kelyi). No field or other official permits have been required for the work.

The most relevant specimens for our study are deposited in Paleontología de Vertebrados, Instituto Miguel Lillo, San Salvador de Tucumán, Argentina (Lagepeton chanarensis); Museu de Ciências Naturais, Universidade Luterana do Brasil, Canoas, Brazil (Ixalerpeton polesinensis); Ruth Hall Museum of Paleontology, Ghost Ranch, Abiquiu, New Mexico, USA (Dromomeron romeri); Texas Vertebrate Paleontology Collections, The University of Texas at Austin, Austin, Texas (Domomeron gregorii); and University of Antananarivo, Antananarivo, Madagascar (Kongonaphon kelyi).

No new dates were obtained for this study. Dates used for the Bayesian inference analysis are provided in the supplementary file of 


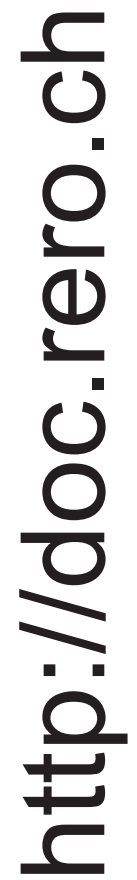

